\title{
Measuring adolescents' tourism satisfaction: The role of mood and perceived parental style
}

\begin{abstract}
Adolescents have become an attractive market for tourism because they represent a sizable population segment with an increasing influence on family purchases. There is an urgent need to understand adolescents'needs, motivations and role in the tourism industry, particularly the factors that may affect their tourism satisfaction. This study highlights the importance of adolescents' mood and the style in which they have been parented as under-researched factors affecting young people's tourism satisfaction. The focus of the study is Alisadr cave, a well-known tourist destination for families in Iran. In 2016, questionnaires were distributed to 360 tourists ranging in age from 11 to 18 years. Descriptive statistics, Pearson's correlation analysis and multiple regressions were run on the 354 useable responses. Results showed, firstly, that $60.2 \%$ of the respondents had high levels of satisfaction with mean scores above 3.5 for all items. Secondly, the dominant parenting style, as perceived by the adolescents, was authoritative. Finally, there was a significant and positive relationship between authoritative parenting style and positive mood in relation to adolescents' basic needs' satisfaction. Authoritarian parenting style and negative mood had a significant and negative relationship with the satisfaction of all three basic needs, namely autonomy, competence and relatedness. Permissiveness had a positive relationship with only two of the needs - autonomy and relatedness.
\end{abstract}

Keywords: Parental style; Adolescent; Tourism satisfaction; Mood; Self-Determination Theory

\section{Introduction}

Children in general and adolescents in particular represent a significant proportion of most national populations (Carr, 2006). The World Health Organization (WHO, 2015) defines "adolescents" as individuals between 10 and 19 years old. Similarly, Carr (2006) stated the core adolescent years are typically defined as between 12 and 17 years old, those years between childhood and adulthood (Spiers, 2017). Adolescents have become an attractive market not only because of their large share of the population and their growing consumption habits but also due to their increasing influence on their family's purchases (Gaumer and Arnone, 2010). In fact, families with adolescents form a significant portion of the sizeable and fast-growing family tourism market (Carr, 2011; Schänzel and Smith, 2014; Small, 2008). The desire of parents to spend extended time with their children may be one of the reasons why, especially once children enter adolescence and begin increasingly to give voice to their own desires, parents are willing to compromise their own holiday wishes to 
ensure the family goes on holiday together (Carr, 2011). The voices presented within families are becoming increasingly inclusive, reflecting the more active participation of children and adolescents within research and family life (Schänzel and Carr, 2016).

Adolescence is viewed as the most traumatic or challenging period of time within the parent-child relationship, since parents can either facilitate or undermine children's intrinsic motivation and internalisation (Joussemet et al., 2008). One of the most studied approaches to understanding parental influences on human development is the concept of parenting style (Gafoor and Kurukhan, 2014). Parental style reflects a family socialisation context in which parents reach their parental goals and transfer values to their children through parenting practices (Bao et al., 2007). Based on Baumrind's (1991) classification, parenting style can be classed as 'authoritative', 'authoritarian' or 'permissive'. Based on Self-Determination Theory (SDT), the three basic psychological needs - namely competence, autonomy, and relatedness - can either be supported or challenged by social contexts, including parenting styles (Ryan and Deci, 2000). In the tourism context, a study by Shavanddasht and Schänzel (2017) suggests specific parenting practices, such as involvement, knowledge, and control, can affect adolescents' motivations and tourism experiences.

In recent years, there have been an increasing number of studies which have investigated relationships between parental styles and children in different sciences such as physical education, education, and psychology and in various fields including school achievement, mental health, selfsatisfaction, well-being, psychological needs, social power, and behavioral problems. Parenting style is then an important aspect to research concerning adolescents. However, in terms of tourism, the significant issue of parental influence on a child's development is under researched. As already noted, there is only one study in which the relationship between adolescents' tourism motivations and their perceived parenting styles has been investigated. In fact, in the study by Shavanddasht and Schänzel (2017) the significant relationship between more self-determined motivations and a more liberal parental style, such as the authoritative parenting style, and less self-determined motivations and a more strict parental style such as the authoritarian parenting style, has been proven. Therefore, taking into account the significance of this factor for tourism studies, there is 
an urgent need to investigate the role of parental styles in other tourism dimensions, such as adolescent satisfaction.

Moreover, many authors have noted that more research about the effects of emotions and mood states on consumer behavior is needed (Holbrook\& Gardner, 2000; Howard \& Gengler, 2001; Gountas \& Gountas, 2004). Holbrook and Gardner (2000) stated that how the moods and emotions affect the consumer's level of satisfaction is the most important question (Gountas \& Gountas, 2004). Khademi (2010) have addressed "mood" as a significant feature of adolescents and Weinstein and Mermelstein (2007) stated that mood and emotional volatility is a well-documented but under-researched feature of adolescence, which also applies for tourism. It means the role of mood as an affective state informing adolescent tourism satisfaction has received scant attention.

This article, then, ensures more attention is paid to these two factors of mood and adolescents, instead of focusing on more 'traditional' aspects of tourism (e.g. motivations and adults). Informed by a conceptual framework, this study investigated the potential relationship between adolescents' needs satisfaction, their perception of the style in which they have been parented, and their mood states, in a tourism context in Iran.

\section{Literature review}

\section{Adolescents, families and tourism}

Families are recognised as a prominent decision-making and consumption unit in marketing, consumer behaviour and the tourism literature (Blichfeldt, 2008; Lehto et al., 2012; Nanda et al., 2007; Spiers, 2017). In relation to research on family holidays, traditionally the parents act as respondents (Nickerson and Jurowski, 2001); firstly, because it is assumed that the parents qualify as reliable respondents (Blichfeldt et al., 2010) and, secondly, because children have traditionally been viewed as unsophisticated or incompetent respondents (Schänzel and Carr, 2016). There are few studies investigating the family holiday experiences of children that treat children as active agents (e.g., Carr, 2006, 2011; Hilbrecht et al., 2008; Small, 2008). Similarly, Carr (2011) indicated that the majority of the studies have tended to provide adult-oriented examinations, generally viewing children as passive objects and, as a result, rarely collecting any information directly from them. 
Studies on family holiday decision-making is a case in point. At first, these studies focused on the husband and wife dyadic and only to a lesser extent on children (Blichfeldt et al., 2010). Blichfeldt et al. (2011) claimed that most researchers argue that children's role in decision-making is a rather passive one and that the parents have the final say (Wang et al., 2004). More recently, the voices of children are being heard and there are increasingly studies that actively include children (e.g., Gram, 2007; Nickerson and Jurowski, 2001; Schänzel and Smith, 2014). As Schor (2004) notes, children today wield far more power in family decision-making processes than has traditionally tended to be the case (Carr, 2011). There are two main reasons: first, children today become more active participants in family decision making process (Therkelsen, 2010; Yeoman et al., 2012). They are "no longer submissive to parental choices, they want to get involved and be a part of the planning process" (Nayak, 2016: 89). Second, as Gram (2007) noted, parents are more willing to listen to them and accommodate their desires, as well as encouraging their children to give active voice to their desires (Carr, 2011). Connell (2005) suggested that the emergent potential of children to be active participants in family decision-making processes is a consequence of more liberal parental styles that have emerged in the latter part of the twentieth century. It becomes very much a two-way process: informed children with supportive parents wanting to ensure quality family time on holiday (Carr, 2011; Gram, 2007).

Today, fulfilling children's needs becomes an integral part of a holiday (Blichfeldt et al., 2010) since parents value the opportunity to spend quality time with their children and this has become ever more desired in modern society (Lehto et al., 2009). In fact, fulfilling children's wishes and keeping them happy is an important aspect of parenting (Schänzel and Yeoman, 2014), especially as a reaction to the perception that parents are too busy and have less time to relax, play, communicate and share meals with their children (Fountain et al., 2015). It is important that children are not considered as a homogenous group as age is a big differentiator (from infancy to adolescence) with different needs at different developmental stages (Schänzel and Yeoman, 2014). Nanda et al. (2007) stated that the place of children in the family and their influence on other family members is likely to depend on their age. Increasing age may also bring an ability to negotiate, thereby creating an expectation of flexibility or willingness to accept compromises not expected from younger children (Khoo-Lattimore et al., 2015). In this way, adolescents have a 
large role in family decision-making processes, including when on holiday. One of the most important reasons for the increasing influence of adolescents is that, "as demographic and social structures are changing, the traditional power relation within the family is altering and this leads to children's growing influence within the family" (Holzmüller, 2014: 17). Spiers (2017) states that adolescents demonstrate better consumer skills and understanding of economic concepts, and are more rational than younger children.

Entering adolescence, children begin to refine and articulate their own holiday motivations and desires as distinct from those of the family and their parents (Decrop, 2005). It is clear that, although becoming independent from their parents may be a primary concern of adolescents, this does not necessarily mean they do not appreciate spending time with them while on holiday. Indeed, Kränzl-Nagl and Beham (2007: 1) stated that even older children "demand attention from their parents and want them to be available for them". Indeed, while it is apparent that a significant number of adolescents do not wish to holiday with their parents, an equally significant number are very happy to do so (Carr, 2011). Overall, there is an urgent need to understand adolescents' needs, motivations and role in the tourism industry, particularly the factors that may affect their tourism satisfaction. This study highlights the importance of adolescents' mood and the style in which they are parented as influencers of their tourism satisfaction, informing the conceptual framework below (Figure 1).

\section{Parental style, Self-Determination Theory, satisfaction}

Parental styles are defined as the behaviours, attitudes, and values parents use to determine how they interact with their children (Cripps and Zyromski, 2009). Baumrind's parental style typology is composed of three distinctive types of parental control: authoritarian, authoritative, and permissive (Bao et al., 2007). Each style demonstrates a particular relationship that occurs between the parents and children at a specific point in time. Firstly, authoritarian parents attempt to shape, control and evaluate the behaviour and attitudes of the child in terms of a set of standards. Obedience is all-important and imposed with harsh punishment (Roman et al., 2016). Children of authoritarian parents are notably "unhappy, fearful, anxious about comparing themselves with others, fail to initiate activity, and have weak communication skills" (Cripps and Zyromski, 2009: 6). Secondly, authoritative parents are warm and nurturing, create a loving home environment and 
provide a high degree of emotional support. Children of parents who exercise the authoritative parenting style are notably "often cheerful, self-controlled, self-reliant, achievement-oriented, maintain friendly relations with peers, cooperate with adults, and cope well with stress" (Santrock, 2004: 277). Finally, Spera (2005: 134) asserted, "permissive parents score moderately high on measures of responsiveness and low on measures of maturity demands and control". This parenting style is associated with immaturity in children, lack of impulse control and self-reliance, and a lack of social responsibility and independence (Starr, 2011).

The type of parenting style used by parents may be determined by the parent's own cultural heritage (Chang, 2007). For example, the majority of studies on Asian parenting consistently show that Asian parents employ a more authoritarian style of parenting compared to Westerners (Chao, 1995; Gorman, 1998; Khoo-Lattimore et al., 2015). For Asians, parental obedience and some aspects of strictness may be equated with parental concern, caring, and involvement (Sorkhabi, 2005). Historically, Iran has been a patriarchal society (Fathi, 1985) and strongly emphasises highly authoritarian parenting, respect for elders and unconditional loyalty to family over personal needs, as well as deference to parental authority (Sharifzadeh, 1998). Touba (1979) concluded that the dominant parenting style in Iran was probably authoritarian. However, in recent decades, particularly because of considerable cultural and political reforms, Iranians have been more willing to accept a more democratic approach to parenting (Alizadeh and Yari, 2006). Most recent studies have found authoritativeness to be the dominant parenting style in Iran (Alami et al., 2014; Derakhshanpour et al., 2016; Shavanddasht and Schänzel, 2017), indicating a significant change in how children are being raised there.

Self-Determination Theory (SDT; Deci and Ryan, 2000, 2008) uses the concept of innate, universal, psychological needs to understand human motivation. All human beings have the fundamental need to feel related, competent, and autonomous in order to develop and function optimally (Deci and Ryan, 2000). The paramount importance given to the need for autonomy is the core feature of SDT (Joussemet et al., 2008). 'Autonomy' refers to the need to feel that one's behaviour and resulting outcomes are self-determined, or self-caused, as opposed to being influenced or controlled by outside forces. 'Competence' refers to the need to feel effective and capable of performing tasks at varying levels of difficulty. 'Relatedness' refers to the need to feel 
connected to, supported by, or cared for by other people (Chang et al., 2015). These distinctive needs are enhanced and developed by tourists when they engage in interesting activities (Allan, 2012). Allan (2012) further indicated that intrinsically motivated people should gain satisfaction from autonomy and competence needs.

A SDT perspective on parenting provides a comprehensive account of the dynamics and mechanisms through which parenting impacts the psychosocial development of children (Skinner et al., 2005). Adolescence is a critical phase of life. Achieving independence and autonomy, setting personal goals and making plans, and acquiring values and ethics are developmental tasks that all adolescents have to realise (Hui and Tsang, 2012). Being self-determined is a developmental task that all young people have to confront and is pertinent to their whole-person development (Hui and Tsang, 2012). During adolescence, parents can create an environment that meets adolescents' needs for autonomy, competence, and relatedness by providing autonomy support, structure, and involvement respectively (Grolnick, 2003; Grolnick and Pomerantz, 2009). Parents are autonomy supportive when they openly discuss rules and disagreements with adolescents, provide choices for how (but not whether) adolescents can follow rules, and acknowledge their child's perspective (Farkas and Grolnick, 2010; Grolnick, 2003). Studies showed that perceived autonomy support from both mothers and fathers was significantly and positively associated with children's own feelings of competence and autonomy (Joussemet et al., 2008). As a result, authoritative parenting is often found to be associated with the best child-development outcomes (e.g., Baumrind, 1978; Maccoby and Martin, 1983). Tong (2015) states that the adolescent children of authoritative parents learn how to competently negotiate and engage in discussions. These adolescents understand that their opinions are valued and as a result are more likely to be socially competent, responsible, and autonomous.

\section{Mood}

Moods occur when the cognitive system is maintained in an emotion mode for a period of time (Bagozzi et al., 1999). In tourism, the word 'mood' is used to refer to how tourists feel during their holidays (Nawijn, 2010). In this study, mood has been defined as a "mild, transient, and generalised affective state" in accordance with most commonly used definitions in the marketing literature (Sirakaya et al., 2004: 520). Researchers suggest that mood can influence the consumption process 
(Chartrand et al., 2006; de Rojas and Camarero, 2008; Huang et al., 2012). As an example, people who are in a good mood evaluate stimuli more positively than do those in a bad or neutral mood. Moods do not interrupt ongoing thought processes and behaviours, but they do colour our day-today experiences (Luong, 2005). According to Huang et al. (2012), some studies have recognised that mood during the acquisition and consumption of the product or service can also have a significant influence on satisfaction judgments (Chartrand et al., 2006; Nawijn, 2010). Therefore, lower levels of satisfaction can be related to bad moods (Luong, 2005). Tourists with lower mood evaluations tended to have lower levels of satisfaction with tourism services. To avoid a biased evaluation such as this, the researcher must try to account for or adjust for the effect of mood when reporting customer satisfaction scores (Nawijn, 2010). In this study, adolescents were chosen as the target population since, firstly, they as tourism consumers are affected by their mood, generally due to being interested or uninterested in a chosen destination. In fact, parents sometimes force children to be with their family during holidays, requiring them to travel as part of a family unit, possibly even against their own will (Poria and Timothy, 2014). Secondly, tourism researchers rarely give voice to adolescents and previous tourism studies have paid little attention to investigating the effects of mood on young people.

\section{Conceptual framework}

The conceptual model of this research is illustrated in Figure 1. Each component of the model is informed by the literature review. According to the conceptual model, perceived parenting style breaks down into three components including authoritative, permissive and authoritarian. Mood as the next variable has two components, namely positive (vigour, calmness and happiness) and negative (anger, confusion, depression, fatigue and tension). Finally, autonomy, competence and relatedness make up components of adolescent tourism needs satisfaction. Subsequently, the model examines how perceived parenting style and mood affect adolescent tourism needs satisfaction. The theoretical underpinning of this model is further discussed in the method section. 


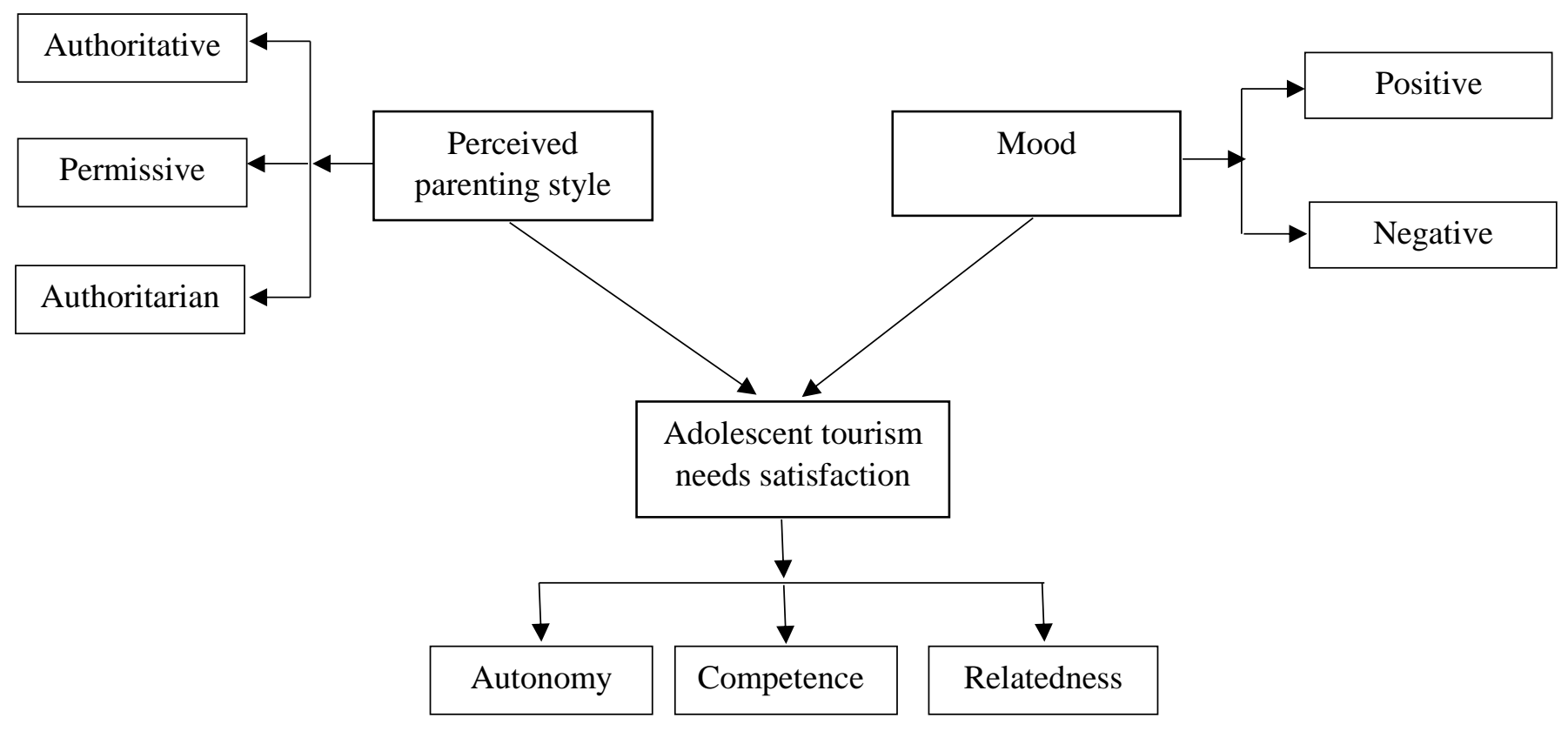

Figure 1. Conceptual framework for measuring adolescents' tourism needs satisfaction.

\section{Study Area}

The Ali Sadr Cave is located about 100 kilometres north of Hamadan in western Iran. As one of the biggest and most remarkable water caves in the world, it is one of the most famous tourist attractions in Iran, attracting thousands of tourists every year (Karimi Soltani, 2015). Ali Sadr Cave is especially popular among families. A study by Shavanddasht et al. (2017) showed $73.2 \%$ of the cave visitors travelled with their family into this place. The cave walls can extend up to 40 metres high, and the cave contains several large, deep lakes. The cave has a river flowing through it and most travel through the cave system happens by pedal boat. "The cave is $2.5 \mathrm{~km}$ long, with the depth of water reaching $8 \mathrm{~m}$ in some parts. The lake water is pellucid and fresh, and the cave contains many caveroneous phenomena including a range of colourful stalactites" (Dowling and Newsome, 2006: 88). The presence of nearby accommodation adds to this established geotourism destination, which is a major natural attraction. Cave tourism is one genre of geotourism (Dowling and Newsome, 2006).

\section{Method}

Participants and procedure 
The target population of this study was adolescents visiting the Alisadr cave on weekdays during the period surveyed, in November 2016. According to Kozak and Decrop (2009), quantitative methods have been intensively used in consumer studies in the tourism literature, including with young people. Using a survey method provides adolescents with autonomy in answering the questions, which differs from younger age groups where qualitative methods are deemed more appropriate (Carr, 2011; Khoo-Lattimore, 2015). Based on the research questions and rational of the study, a survey method was deemed most appropriate. Using a convenience sampling technique, a targeted sample of 354 visitors was chosen. It should be noted that all parents gave permission for their children's participation in the study.

Of these respondents, 181 (51.1\%) were male and the remaining 173 (48.8\%) were female, ranging in age from 11 to 18 years (see Table 1). As Table 1 shows, most adolescents were 18 years old and least were 16 years old, but, overall, the age distribution was even. The table also shows that $91.2 \%$ of respondents lived with their mother and father while the remaining $(8.75 \%)$ were being raised by a single parent.

Table 1. Age and gender of the participants (total $\mathrm{N}=354$ ).

\begin{tabular}{ccc}
\hline Variable & $\mathbf{N}$ & $\mathbf{\%}$ \\
\hline Gender: & & \\
Male & 181 & 51.1 \\
Female & 173 & 48.8 \\
Age (years): & & \\
11 & 45 & 12.7 \\
12 & 43 & 12.1 \\
13 & 41 & 11.5 \\
14 & 48 & 13.5 \\
15 & 50 & 14.1 \\
16 & 32 & 9.0 \\
17 & 37 & 10.4 \\
18 & 58 & 16.3 \\
Parental status: & & \\
\hline
\end{tabular}




\begin{tabular}{lll}
\hline One-parent home & 31 & 8.8 \\
Two-parent home & 323 & 91.2 \\
\hline
\end{tabular}

The questionnaires were completed outside the cave by the young people immediately after they had finished their visit and without the presence of their parents. The duration of each adolescent's participation was approximately 10-20 minutes. Pretesting was conducted on a sample of thirty adolescents, the results of which were not included in the study.

\section{Measures}

The adolescents self-reported their demographic data (age, one- or two-parent family, and gender). In addition, they completed a perceived parenting styles measure (Parental Authority Questionnaire [PAQ]; Buri, 1991), a measure of mood states (Mood Scale; Lane and Jarrett, 2005) and basic needs satisfaction scale (Basic Psychological Needs Satisfaction [BPNS]; Allan, 2012).

The Parental Authority Questionnaire (PAQ) is a 30-item measure divided into three categories ten pertaining to permissive parenting; ten pertaining to authoritarian parenting; and ten pertaining to authoritative parenting. Every participant filled in two questionnaires measuring these three parenting styles separately for fathers and mothers to account for potential gender differences. The participants were asked to reflect on their experiences with their parents since childhood and complete the PAQ based on these experiences. The measure was based on a five-point Likert scale with anchors ranging from $1=$ 'strongly disagree' to $5=$ 'strongly agree'. The Cronbach alpha for scores for the present sample scale was 0.78 .

The Mood Scale is a 16-item measure of the mood states of individuals across eight domains including Anger, Confusion, Depression, Fatigue, Tension, Vigour, Calmness and Happiness.

- Anger items include 'Bad-tempered' and 'Angry';

- Confusion items include 'Mixed-up' and 'Uncertain';

- Depression items include 'Depressed' and 'Downhearted';

- Fatigue items include 'Worn out' and 'Tired';

- Tension items include 'Anxious' and 'Panicky'; 
- Vigour items include 'Alert' and 'Energetic';

- Calmness items include 'Calm' and 'Relaxed';

- Happiness items include 'Cheerful' and 'Happy'.

In this study, Anger, Confusion, Depression, Fatigue and Tension were considered as negative moods and Vigour, Calmness and Happiness were in a positive mood category. Again, participants responded by choosing from a five-point Likert scale (ranging from $1=$ 'strongly disagree', to $5=$ 'strongly agree'). In the present sample, scores from the positive mood subscale achieved a Cronbach alpha score of 0.74 , while those from the negative mood subscale achieved an alpha score of 0.65 .

The Basic Psychological Needs Satisfaction (BPNS) scale assesses the satisfaction of the three basic psychological needs, namely competence, autonomy and relatedness. The scale is made up of 10 items. It is scored on a five-point Likert scale (ranging from $1=$ 'strongly disagree', to $5=$ 'strongly agree'). The Cronbach's alpha coefficient was obtained at $0.68,0.82$ and 0.76, respectively, for autonomy, competence and relatedness, which indicated appropriate tool reliability. Hence, the Cronbach alpha score for this scale in the present sample was 0.75 .

\section{Data analysis}

The data were analysed using SPSS version 22. Descriptive statistics were examined to allow for the appropriate interpretations of the distribution and analyses (see Table 2 for descriptive statistics). In terms of inferential statistics, linear regression analyses were conducted to examine the relations between study variables. Pearson's correlations were conducted to determine the relationships among parenting styles, adolescents' satisfaction, and their mood states (see Table 3 for correlations between the major study variables). Independent variables of the study were authoritative parenting style, authoritarian parenting style, permissive parenting style and mood states. Dependent variables of the study were tourist satisfaction subscales including autonomy, competence and relatedness.

\section{Findings}

Description of the research variables 
The research variables, including the three demographic variables of the respondents, are described with percentages (for the respondents' demographic variables) and means and standard deviations (for other research variables). The data analysis results that describe these variables are presented in Tables 1 and 2. Table 2 shows the mean Likert score and standard deviation for each major variable in this study. In terms of parenting styles, the parenting style of a mother and a father from the same family were very similar, therefore, those two scores were added and divided by two to get a mean perceived parenting score for that family.

For perceived parenting styles, children perceived the parent's influence on them as more authoritative $(\mathrm{M}=3.36, \mathrm{SD}=0.81)$ than authoritarian $(\mathrm{M}=2.84, \mathrm{SD}=0.76)$ or permissive $(\mathrm{M}=$ 2.56, $\mathrm{SD}=0.97)$.

Table 2. Mean Likert scores ( 1 = 'strongly disagree', to $5=$ 'strongly agree') of the major variables (ordered from highest to lowest) with standard deviations (SD).

\begin{tabular}{lll}
\hline Variable & Mean & SD \\
\hline Relatedness & 3.63 & .62 \\
Competence & 3.58 & .91 \\
Autonomy & 3.52 & .67 \\
Authoritative parents & 3.36 & .81 \\
Positive mood & 3.31 & .67 \\
Authoritarian parents & 2.84 & .76 \\
Permissive parents & 2.56 & .97 \\
Negative mood & 2.44 & .61 \\
\hline
\end{tabular}

\section{Relationships between perceived parenting styles and different motivations}

Pearson's bivariate correlations between mood states including positive mood and negative mood, and the three kinds of parenting style - authoritative, authoritarian and permissive - and also the satisfaction of the basic needs - autonomy, competence and relatedness - were conducted.

Table 3. Pearson's correlations (r) between basic needs satisfaction, mood and perceived parenting style $(* *=\mathrm{p}<0.01)$. 


\begin{tabular}{lllllll}
\hline & \multicolumn{3}{l}{ Perceived parenting style } & & \multicolumn{2}{l}{ Mood } \\
\cline { 2 - 4 } \cline { 6 - 6 } Basic need & Authoritative & Permissive & Authoritarian & & Positive & Negative \\
\hline Autonomy & $.573^{* *}$ & $.297^{* *}$ & $-.653^{* *}$ & & $.428^{* *}$ & $-.452^{* *}$ \\
Competence & $.668^{* *}$ & -.110 & $-.460^{* *}$ & & $.229^{* *}$ & $-.542^{* *}$ \\
Relatedness & $.483^{* *}$ & $.233^{* *}$ & $-.627^{* *}$ & & $.457^{* *}$ & $-.439^{* *}$ \\
\hline
\end{tabular}

The correlation matrix in Table 3 shows several pairs of significantly correlated variables. The strongest correlation was between authoritative parenting style and competence $\left(\mathrm{r}=0.668^{* *}\right)$, whereas the lowest correlation was between positive mood and competence responses $(\mathrm{r}=.229 * *)$. Table 3 illustrates that there were positive correlations among authoritative parenting style as an independent variable and all dependent variables, namely autonomy $\left(\mathrm{r}=.573^{* *}, \mathrm{p}<0.01\right)$, competence $\left(r=.668^{* *}, \mathrm{p}<0.01\right)$ and also relatedness $\left(\mathrm{r}=.483^{* *}, \mathrm{p}<0.01\right)$, with correlations described as moderate, strong and moderate respectively, whereas it shows all of these dependent variables were significantly and negatively related to authoritarianism. There were two strong $(r=$ $\left.-.653^{* *}, \mathrm{p}<0.01\right),\left(\mathrm{r}=-.627^{* *}, \mathrm{p}<0.01\right)$ and one moderate $\left(\mathrm{r}=-.460^{* *}, \mathrm{p}<0.01\right)$ correlations between them. The negative mood had the same conditions. All of the basic needs show moderate negative correlations with this independent variable, including autonomy $\left(r=-.452^{* *}, p<0.01\right)$, competence $\left(\mathrm{r}=-.542^{* *}, \mathrm{p}<0.01\right)$ and relatedness $\left(\mathrm{r}=-.439^{* *}, \mathrm{p}<0.01\right)$. The positive mood had moderate positive correlations with autonomy $\left(\mathrm{r}=.428^{* *}, \mathrm{p}<0.01\right)$ and relatedness $\left(\mathrm{r}=.457^{* *}, \mathrm{p}<0.01\right)$ and a weak positive correlation with competence $\left(r=.229^{* *}, p<0.01\right)$. Finally, autonomy $\left(r=.297^{* *}, p\right.$ $<0.01)$ and relatedness $\left(\mathrm{r}=.233^{* *}, \mathrm{p}<0.01\right)$ were significantly and positively related to permissiveness.

Table 4. Results of the regression analyses between basic needs satisfaction, moods and perceived parenting styles $(\mathrm{N}=354)$.

\begin{tabular}{|c|c|c|c|c|c|c|c|c|c|}
\hline \multirow{2}{*}{$\begin{array}{l}\text { Independent } \\
\text { variable }\end{array}$} & \multicolumn{3}{|c|}{ Autonomy } & \multicolumn{3}{|c|}{ Competence } & \multicolumn{3}{|c|}{ Relatedness } \\
\hline & $\mathbf{B u}$ & S.E. & $\beta \sigma$ & $\mathbf{B u}$ & S.E. & $\beta \sigma$ & $\mathbf{B u}$ & S.E. & $\beta \sigma$ \\
\hline Authoritative & .265 & 118 & .320 & .502 & .118 & .446 & .283 & .125 & .236 \\
\hline Permissive & .102 & .114 & .116 & -.240 & .100 & -.200 & .152 & .072 & .164 \\
\hline Authoritarian & -.236 & .094 & -.343 & -.241 & .112 & -.257 & -.340 & .081 & -.534 \\
\hline
\end{tabular}




\begin{tabular}{llllllllll}
\hline Positive Mood & .173 & .075 & .174 & .178 & .100 & .131 & .118 & .072 & .128 \\
Negative Mood & -.160 & .097 & -.153 & -.215 & .130 & -.144 & -.150 & .094 & -.149 \\
& & & & & & & & & \\
F-statistic & 26.358 & & & 27.999 & & 21.177 & \\
p-value & .000 & & & .000 & & & .000 & \\
R & .686 & & & .697 & & .646 & \\
R2 & .471 & & & .486 & & .417 & \\
Adj. R2 & .453 & & .469 & & .397 & \\
Durbin-Watson & 2.471 & & & & & & & \\
\end{tabular}

$\mathrm{Bu}=$ unstandardised beta coefficient; S.E. $=$ standard error of beta, $\beta \sigma=$ standardised beta coefficient

Moreover, a series of linear regression analyses were conducted to examine the relationships between mentioned variables (Table 4). According to Table 4, in relation to autonomy, the results of the regression analysis indicated that authoritative parenting style $(\beta \sigma=.320, p<.001)$, permissive parenting style $(\beta \sigma=.116, \mathrm{p}<.001)$ and positive $\operatorname{mood}(\beta \sigma=.174, \mathrm{p}<.001)$ were significant predictors of autonomy. The overall model explained $47 \%$ of variance in autonomy, which was revealed to be statistically significant, $\mathrm{F}=26.358, \mathrm{p}<.001$. The results of examination of beta coefficients indicated that authoritative parenting style $(\beta \sigma=.446, p<.001)$ and positive $\operatorname{mood}(\beta \sigma=.131, \mathrm{p}<.001)$ were positive predictors for competence. The overall model explained $48 \%$ of variance in competence, which was revealed to be statistically significant, $\mathrm{F}=27.999$, $\mathrm{p}<.001$; whilst authoritativeness $(\beta \sigma=.236, \mathrm{p}<.001)$, permissiveness $(\beta \sigma=.164, \mathrm{p}<.001)$ and positive mood $(\beta \sigma=.128, \mathrm{p}<.001)$ were significant predictors for relatedness. In terms of the relatedness, the overall model explained $41 \%$ of the variance in this dependent variable, which was revealed to be statistically significant, $\mathrm{F}=21.177, \mathrm{p}<.001$.

\section{Discussion}

This study investigated how perceived parenting style and mood affect adolescents' needs satisfaction in a tourism context in Iran. The investigation of the relationships between these variables was twofold. First, Pearson's bivariate correlations between the needs' satisfaction explicated above (autonomy, competence and relatedness) with mood states (positive and 
negative) and perceived parental style were calculated to check the correlations between these constructs. Second, a series of linear regression analyses were conducted to examine the relationships between all these variables. The types of parental styles and mood states served as independent variables, whereas autonomy, competence and relatedness were entered as dependent variables. According to the results, authoritativeness was the dominant parenting style perceived by the adolescents. The result is in line with other studies which found authoritativeness as the dominant parenting style in Iran (Alami et al., 2014; Derakhshanpour et al., 2016; Shavanddasht and Schänzel, 2017). Moreover, there was little gender difference in parental styles between fathers and mothers in this study.

Additionally, most of the adolescents were in a positive mood $(\mathrm{M}=3.31, \mathrm{SD}=0.67)$ rather than a negative $\operatorname{mood}(\mathrm{M}=2.44, \mathrm{SD}=0.61)$ (Table 2$)$. The tourism experience being researched resulted in high levels of satisfaction, since all mean Likert scores for the satisfaction items were above 3.5 (Table 2). Of the three basic needs satisfaction, relatedness had the highest mean score $(\mathrm{M}=3.63$, $\mathrm{SD}=0.62)$, followed by competence $(\mathrm{M}=3.58, \mathrm{SD}=0.91)$ and then autonomy $(\mathrm{M}=3.52, \mathrm{SD}=$ $0.67)$.

In the relationship between perceived parenting style, mood state and basic needs satisfaction, this study firstly found a significant and negative relationship between authoritarianism, negative mood and all three needs' satisfactions. Based on the literature, feeling autonomous refers to having a sense of choice. Feeling competent corresponds to having a sense of mastery over one's capacity to act in the environment. Relatedness refers to feelings of closeness and connectedness to significant others (Veronneau et al., 2005). Chan and Chan (2005) described the authoritarian parenting style as confining and punishing. Parents using this parenting style enforce strict boundaries and restraints on adolescents and allow only a minute amount of compromise (Santrock, 2004). In this way, parents actively thwart or block the satisfaction of psychological needs (Cordeiro et al., 2015); as Gram (2007) stated, if the child does not wish to go to a tourism site, the likelihood of getting satisfied children is poor. Children and adolescents are likely to have less control over their activity engagement than adults. Thus, weak effects for pleasant activities may be attributable to such activities being chosen by others versus self-selected and are, hence, less rewarding (Weinstein and Mermelstein, 2007). As Carr (2011) noted, the potential for intra- 
familial conflict and dissatisfaction with the holiday experience is potentially heightened if the desires of each member of the family are not taken into account. Ignoring the role of adolescents in tourism decision-making process is exactly what authoritarian parents do, since they are in the dominant position and assume that their children will submit to whatever choices they make, including their (parents') choice of holiday destination.

Past studies show there is a direct and negative relationship between negative mood and satisfaction (Huang et al., 2012; de Rojas and Camarero, 2008), which is consistent with the result of this study. Nawijn (2010) claimed that tourists with lower mood evaluations tended to have lower levels of satisfaction with tourism services, and Sirkaya et al. (2004) stated that lower levels of satisfaction are related to bad (lower) mood. However, Sirkaya et al. (2004) did not examine the relationship between parental style and mood states, but, as previous studies noted, children's mood states can be negatively affected by excessive parental control (Soenens et al., 2008; Nanda et al., 2012). Moreover, Reis et al. (2000) indicated that activities that detract from autonomy would have negative effects on mood.

Secondly, there was a significant and positive relationship between authoritativeness and positive mood with the satisfaction of the needs for autonomy, competence and relatedness. In fact, parents using authoritative techniques allow compromise and are noted as being the most flexible in their regulation of behaviours. Regulation of behaviours is conducted through explanation rather than enforcing stern punishment (Chan and Chan, 2005). Li et al. (2017) found that the involvement of children in the decision-making process could improve the family's holiday satisfaction. Connell (2005) found that parents in contemporary society are providing more opportunities for their children to participate in family decision-making, and Decrop (2005) also stated they take their children into consideration when choosing holiday activities. This so called "liberal parental style" is further explained by Carr (2011), who claims that children are offered more money and freedom in tourism consuming processes because of their parents' guilt over their frequent absences from their children's daily life. Consequently, children are more willing to express their desires and participate in the decision-making process (Gram, 2007). Therefore, children nowadays have a more observable influence on family holidays than ever before (Li et al., 2017) and, consequently, have higher self-esteem, social competence, autonomy, and are better behaved (Spera, 2005; Tong, 
2015). As mentioned before, studies in marketing and tourism (e.g., Huang et al., 2012; Nawijn, 2010; de Rojas and Camarero, 2008; Weinstein and Mermelstein, 2007) confirm a significant relationship between mood and satisfaction. In fact, customers provide more favourable evaluations of services, places, objects, or ideas while in positive mood states (Sirkaya et al., 2004). Accordingly, tourists who are in a good mood and feel positive emotions are more satisfied with their tourism experience.

In terms of permissiveness, there was a positive and significant relationship between this parental style and the satisfaction of needs for autonomy and relatedness. In fact, parents who use the permissive parenting style require nothing; they completely accept and submit to their adolescents (Santrock, 2004). These parents are ready to sacrifice their holiday time for their children. Besides the external pressure on children to request/demand more, and more actively, of their parents, and on parents to submit to this (Carr, 2011), the guilt associated with a perception by parents that they are not spending sufficient time with their children is leading to the latter having more say in family holiday decisions (Wang et al., 2004). In addition, the direct active influence of children in the family holiday decision-making process increases significantly as they enter adolescence. Hence, permissiveness may fulfil the autonomy and relatedness needs of adolescents in a tourism destination.

The other need of SDT is competence. Competence refers to the qualification, capability and efficiency of an individual when (s)he performs an action (Allan, 2012). When the need for competence is thwarted, people feel incapable and inferior (de Haan et al., 2013). Interestingly, in the present study, competence was significantly and negatively related to permissiveness. Grolnick et al. (2000) found that higher levels of parental involvement were related to higher child competence, whereas parents who use the permissive parenting style establish miniscule amounts of control and are unavailable to guide their children through decision-making processes (Chan and Chan, 2005). Finally, the results of the regression analysis revealed that authoritative parenting style, permissive parenting style and positive mood were significant predictors for autonomy and relatedness. The study further revealed that competence in adolescents was significantly predicted by the authoritative parenting style and positive mood. 


\section{Conclusions}

Generally, many tourism and hospitality businesses track the satisfaction of their customers via surveys. By identifying the significant dimensions of tourist satisfaction, tourism organisations and travel researchers can sensitively analyse the causes of general satisfaction/dissatisfaction and rectify them accordingly (Shavanddasht et al., 2017). The tourism industry has increasingly recognized the value of children, since children nowadays have undeniable influence on family holidays compared to previous times. The level of children's influence on the family holiday is believed to increase with increasing age. In this way, adolescents have a more important role in family holiday decisions when compared with younger children.

While surveys are useful, there are factors that can interfere with consumers' evaluations of services by biasing or hiding true satisfaction scores. For example, the mood or state of being of the consumer during the evaluation might contribute to erroneous measures of their satisfaction levels (Sirakaya, 2003). In this study, basic needs satisfaction has been found to be positively associated with positive and pleasant mood, while dissatisfaction was related to negative and unpleasant mood. Moreover, based on results, perceived parental style could be another factor affecting tourist satisfaction, particularly for adolescents. According to the research findings, it can be concluded that authoritativeness in parental style has significant and positive influences on children's satisfaction. Children of authoritative parents showed high levels of satisfaction gained from tourist experiences in all of the three basic psychological needs of autonomy, competence and relatedness; whereas adolescents with authoritarian parents expressed lower levels of satisfaction and even dissatisfaction in their tourism experiences. In terms of permissiveness, there was a positive and significant relationship between this parental style and the satisfaction of autonomy and relatedness needs. Overall, authoritative parenting adopting a warm but firm approach to parenting allows adolescents to be independent within developmentally appropriate parental limits and boundaries. Hence, authoritativeness could help families to have a more satisfactory holiday experience where all of the family members' desires and needs are met and intra-family conflict is consequently reduced, which could further add to the satisfaction of the family members with their holiday experiences. 
In conclusion, the research reported here has both theoretical and pragmatic implications. Accounting for the influence of mood and perceived parental style on adolescents' satisfaction ratings provides information useful for both academic researchers and marketers. Ignoring the roles of perceived parenting style and mood states as effective factors on tourism satisfaction may give a false sense of security to tourism companies, especially when satisfaction scores are either high or low. Studying the effect of these factors in a tourism context also enhances the general consumer behaviour literature and lays the foundations for further investigations in different tourism settings where customer evaluations of tourism products play an important role in predicting success or failure (Sirakaya et al., 2004). The findings have a practical use in assessing the basic needs of tourists who are not sufficiently satisfied with their experiences. With better information, strategies can be developed to help these tourists overcome their deficits in needs satisfaction. In this study, adolescents were chosen as the target population since adolescence is a critical phase of life during which young people face physical, psychological, intellectual and emotional concerns and challenges, search for self-identity, explore new roles and deal with the transition to secondary schools and, later, from school to work and adulthood. Being selfdetermined is a developmental task that all young people have to confront and is pertinent to their whole-person development (Hui and Tsang, 2012).

In summary, although the findings of this study are by no means conclusive, they do strongly suggest that mood states and adolescents' perception of parenting styles have an effect on how a tourism product will be evaluated by young people as well as their level of satisfaction at the end of their visit. Tourism and hospitality researchers may incorporate affective factors, such as mood and the way in which young consumers perceive they have been parented, into decision-making and customer satisfaction studies. Logically, the results obtained are not free of limitations, as they were taken from a study in a specific geographical area at a specific time of year. It is recommended that further research be undertaken in exploring the relationships among these variables in different tourism settings, countries, samples and times of the year in order to test and further generalise the findings. However, this study is a first to address the link between parental styles, mood states and needs satisfaction from the perspective of adolescents within a tourism context, thus furthering our understandings of the influences on young people's behaviour. 


\section{References}

Alami A, Khosravan S, Sadegh Moghadam, L, et al. (2014) Adolescents' self-esteem in single and twoparent families. International Journal of Community Based Nursing and Midwifery 2(2): 69-76.

Alizadeh H and Yari M (2006) Parenting styles in Iranian families of adolescents with and without conduct disorder. Research on Exceptional Children 20: 695-696.

Allan M (2012) Geotourism: Toward a Better Understanding of Motivations for a Geotourism Experience, a Self-Determination Theory Perspective. Saarbrücken, Germany: Lambert Academic Publishing.

Bagozzi RP, Gopinath M and Nyer PU (1999) The role of emotions in marketing. Journal of the Academy of Marketing Science 27(2): 184-206.

Bao Y, Fern EF and Sheng S (2007) Parental style and adolescent influence in family consumption decisions: An integrative approach. Journal of Business Research 60(7): 672-680.

Baumrind D (1978) Parental disciplinary patterns and social competence in children. Youth and Society 9: 239-276.

Baumrind D (1991) The influence of parenting styles on adolescent competence and substances. Journal of Early Adolescence 11: 58-95.

Blichfeldt BS (2008) What to do on our holiday: The case of in situ decision-making. Anatolia 19(2): 287305.

Blichfeldt BS, Pedersen B, Johansen A, et al. (2010) Tween tourists: Children and decision-making. Journal of Tourism Consumption and Practice 2(1): 1-24.

Blichfeldt BS, Pedersen BM, Johansen A, et al. (2011) Tweens on holidays: In-situ decision-making from children's perspective. Scandinavian Journal of Hospitality and Tourism 11(2): 135-149.

Buri JR (1991) Parental authority questionnaire. Journal of Personality and Social Assessment 57: 110119.

Carr N (2006) A comparison of adolescents' and parents' holiday motivations and desires. Tourism and Hospitality Research 6(2): 129-142.

Carr N (2011) Children's and Families' Holiday Experiences. London, England: Routledge.

Chan K and Chan S (2005) Perceived parenting styles and goal orientations: A study of teacher education students in Hong Kong. Research in Education 74: 9-21.

Chang JH, Huang CL and Lin YC (2015) Mindfulness, basic psychological needs fulfillment, and wellbeing. Journal of Happiness Studies 16: 1149-1162.

Chang M (2007) Cultural Differences in Parenting Styles and their Effects on Teens' Self-Esteem, Perceived Parental Relationship Satisfaction, and Self-Satisfaction. Honours Thesis, Carnegie Mellon University, Pittsburgh, PA. 
Chao RK (1995) Chinese and European American cultural models of the self-reflected in mothers' childrearing beliefs. Ethos 23(3): 328-354.

Chartrand TL, Von Baaren R and Bargh JA (2006) Linking automatic evaluation to mood and information processing style: Consequences for experienced affect, impression formation, and stereotyping. Journal of Experimental Psychology-General 135(1): 70-77.

Connell J (2005) Toddlers, tourism and tobermory: Destination marketing issues and television-induced tourism. Tourism Management 26(5): 763-776.

Cordeiro P, Paixão MP and Lens W (2015) Perceived parenting and basic need satisfaction among Portuguese adolescents. Spanish Journal of Psychology 18(62): 1-15.

Cripps K and Zyromski B (2009) Adolescents' psychological well-being and perceived parental involvement: Implications for parental involvement in middle schools. Research in Middle Level Education Online 33(4): 1-13.

Deci EL and Ryan RM (2000) The "what" and "why" of goal pursuits: Human needs and the selfdetermination of behaviour. Psychological Inquiry 11: 227-268.

Deci EL and Ryan RM (2008) Facilitating optimal motivation and psychological well-being across life's domains. Canadian Psychology 49: 14-23.

Decrop A (2005) Group processes in vacation decision-making. Journal of Travel and Tourism Marketing 18(3): 23-36.

De Haan AD, Soenens B, Dekovic' M, et al. (2013) Effects of childhood aggression on parenting during adolescence: The role of parental psychological need satisfaction. Journal of Clinical Child \& Adolescent Psychology 42: 393-404.

Derakhshanpour F, Khaki S, Shahini N, et al. (2016) A survey of the relationship between mental health with parenting styles in mothers of children with attention deficit hyperactivity disorder. Journal of Fundamentals of Mental Health 18(3): 151-155.

De Rojas C and Camarero C (2008) Visitors' experience, mood and satisfaction in a heritage context: Evidence from an interpretation center. Tourism Management 29(3): 525-537.

Dowling R and Newsome D (eds) (2006) Geotourism. Oxford, England: Elsevier.

Farkas MS and Grolnick WS (2010) Examining the components and concomitants of parental structure in the academic domain. Motivation and Emotion 34: 266-279.

Fathi A (1985) Social interaction in the traditional urban Iranian family. In: Fathi A (ed) Women and the Family in Iran. Leiden, the Netherlands: Brill, pp. 151-157.

Fountain J, Schänzel H, Stewart E, et al. (2015) Family experiences of visitor attractions in New Zealand: Differing opportunities for 'family time' and 'own time'. Annals of Leisure Research 18: 342-358. 
Foxman ER, Tansuhaj PS and Ekstrom KM (1989) Family members' perceptions of adolescents' influence in family decision making. Journal of Consumer Research 15(4): 482-491.

Gafoor A and Kurukhan A (2014) Construction and validation of scale of parenting style. Guru Journal of Behavioural and Social Sciences 2: 315-323.

Gaumer CJ and Arnone C (2010) Grocery store observation: Parent-child interaction in family purchases. Journal of Food Production Marketing 16(1): 1-18.

Gorman JC (1998) Parenting attitudes and practices of immigrant Chinese mothers of adolescents. Family Relations 47(1): 73-80.

Gountas S and Gountas JY (2004) The influence of counsumers' emotions on their service product evaluations. Tourism Analysis 8: 125-128.

Gram M (2007) Children as co-decision makers in the family? The case of family holidays. Young Consumers 8(1): 19-28.

Grolnick WS (2003) The Psychology of Parental Control: How Well-Meant Parenting Backfires. Mahwah, NJ: Lawrence Erlbaum Associates Publishers.

Grolnick WS, Kurowski CO, Dunlap KG, et al. (2000) Parental resources and the transition to junior high. Journal of Research on Adolescence 10: 465-488.

Grolnick WS and Pomerantz EM (2009) Issues and challenges in studying parental control: Toward a new conceptualization. Child Development Perspectives 3: 165-170.

Hilbrecht M, Shaw SM, Delamere FM, et al. (2008) Experiences, perspectives, and meanings of family vacations for children. Leisure/Loisir 32(2): 541-571.

Holbrook B and Gardner MP (2000) Illustrating a dynamic model of the mood-updating process in consumer behaviour. Psychology \& Marketing 17(3): 165-194.

Holzmüller V (2014) Strategies of children and parents during shopping for groceries. Young Consumers 15(1): 17-36.

Howard DJ and Gengler C (2001) Emotional contagion effects on product attitudes. Journal of Consumer Research 28(2): 189-211.

Huang Y, Scott N, Ding P, et al. (2012) Impression of Liusanjie: Effect of mood on experience and satisfaction. International Journal of Tourism Research 14: 91-102.

Hui E and Tsang S (2012) Self-determination as a psychological and positive youth development construct. The Scientific World Journal 1-7.

Joussemet M, Landry R and Koestner R (2008) A self-determination theory perspective on parenting. Canadian Psychology 49: 194-200. 
Karimi Soltani P (2015) A survey on the tourists' role in the changes of the relative humidity percentage inside the caves (case study: Alisadr cave, Hamedan). Journal of Current Research in Science 3(2): $10-15$.

Khademi M (2010) Mood and bipolar disorder in children and adolescents. Tehran: Ghatre publishing, first edition.

Khoo-Lattimore C (2015) Kids on board: Methodological challenges, concerns and clarifications when including young children's voices in tourism research. Current Issues in Tourism 18(9): 845-858.

Khoo-Latimore C, Prayag G and Cheah BL (2015) Kids on board: Exploring the choice process and vacation needs of Asian parents with young children in resort hotels. Journal of Hospitality Marketing \& Management 24: 511-531.

Kozak M and Decrop A (eds) (2009) Handbook of Tourist Behavior: Theory \& Practice. New York, NY: Taylor \& Francis.

Kränzl-Nagl R and Beham M (2007, December). Time Poverty or Time Welfare in Austrian Families? Impact of Family Factors on Children's School Achievements [Policy Brief]. Vienna, Austria: European Centre for Social Welfare.

Lane AM and Jarrett H (2005) Mood changes following golf among senior recreational players. Journal of Sports Science \& Medicine 4: 47-51.

Lehto XY, Choi S, Lin YC, et al. (2009) Vacation and family functioning. Annals of Tourism Research 36(3): 459-479.

Lehto XY, Lin Y-C, Chen Y, et al. (2012) Family vacation activities and family cohesion. Journal of Travel \& Tourism Marketing 29(8): 835-850.

Li M, Wang D, Xu W, et al. (2017) Motivation for family vacations with young children: Anecdotes from the Internet. Journal of Travel \& Tourism Marketing.

Luong A (2005) Affective service display and customer mood. Journal of Service Research 8: 117-130.

Maccoby EE and Martin JA (1983) Socialization in the context of the family: Parent-child interaction. In: Hetherington EM (ed) Handbook of Child Psychology: Vol. 4. Socialization, Personality, and Social Development (4 ed). New York, NY: Wiley, pp. 1-101.

Nanda D, Hu C and Bai B (2007) Exploring family roles in purchasing decisions during vacation planning. Journal of Travel \& Tourism Marketing 20: 107-125.

Nanda MM, Kotchick BA and Grover RL (2012) Parental psychological control and childhood anxiety: The mediating role of perceived lack of control. Journal of Child and Family Studies 21: 637-645.

Nawijn J (2010) The holiday happiness curve: A preliminary investigation into mood during a holiday abroad. International Journal of Tourism Research 12: 281-290. 
Nayak RS (2016) Parent-adolescent conflict and choice of conflict resolution strategy. International Journal of Conflict Management 27(1): 88-115.

Nickerson N and Jurowski C (2001) The influence of children on vacation travel patterns. Journal of Vacation Marketing 7(1): 19-30.

Poria Y and Timothy DJ (2014) Where are the children in tourism research? Annals of Tourism Research 47: 93-95.

Reis HT, Sheldon KM, Gable SL, et al. (2000) Daily well-being: The role of autonomy, competence, and relatedness. Personality \& Social Psychology Bulletin 26: 419-435.

Roman NV, Makwakwa T and Lacante M (2016) Perceptions of parenting styles in South Africa: The effects of gender and ethnicity. Cogent Psychology 3(153231): 1-12.

Ryan RM and Deci EL (2000) Self-determination theory and the facilitation of intrinsic motivation, social development, and well-being. American Psychologist 55: 68-78.

Santrock JW (2004) Life-Span Development (9 ed). New York, NY: McGraw-Hill.

Schänzel H and Carr N (2016) Introduction: Special Issue on children, families and leisure - part three. Annals of Leisure Research 19(4).

Schänzel HA and Smith KA (2014) The socialization of families away from home: Group dynamics and family functioning on holiday. Leisure Sciences 36(2): 1-18.

Schänzel HA and Yeoman I (2014) The future of family tourism. Tourism Recreation Research 39(3): 343360.

Schor J (2004) Born to Buy: The Commercialized Child and the New Consumer Culture. New York, NY: Scribner.

Sharifzadeh VS (1998) Families with Middle Eastern roots. In: Lynch EW and Hanson MJ (eds) Developing Cross-Cultural Competence: A Guide for Working with Children and their Families. Baltimore, MD: Paul H. Brookes, pp. 441-482.

Shavanddasht M, Karubi M and Nekouie Sadry B (2017) An examination of the relationship between cave tourists' motivations and satisfaction: The case of Alisadr Cave, Iran. GeoJournal of Tourism and Geosites 20: 165-176.

Shavanddasht M and Schänzel HA (2017) Effects of perceived parental style on adolescents' motivations in a tourism context. Anatolia 28(2): 263-275.

Sirakaya E (2003) Measuring customer satisfaction: Are you measuring what you are supposed to be measuring? e-Review of Tourism Research (eRTR) 1(4): 53-55.

Sirakaya E, Petrick J and Choi HS (2004) The role of mood on tourism product evaluations. Annals of Tourism Research 31: 517-539. 
Skinner EA, Johnson SJ and Snyder T (2005) Six dimensions of parenting: A motivational model. Parenting: Science and Practice 5: 175-235.

Small J (2008) The absence of childhood in tourism studies. Annals of Tourism Research 35(3): 772-789.

Soenens B, Luyckx K, Vansteenkiste M, et al. (2008) Clarifying the link between parental psychological control and adolescents' depressive symptoms: Reciprocal versus unidirectional models. MerrillPalmer Quarterly 54: 411-444.

Sorkhabi N (2005) Applicability of Baumrind's parent typology to collective cultures: Analysis of cultural explanations of parent socialization effects. International Journal of Behavioural Development 29: $552-563$.

Spera C (2005) A review of the relationship among parenting practices, parenting styles, and adolescent achievement. Educational Psychology Review 17(2): 125-146.

Spiers M (2017) Families with Adolescents: Vacation Decision Making. PhD Thesis, Victoria University of Melbourne, Australia.

Starr ML (2011) The Relationship between Parenting Styles, Learning, Autonomy, and Scholastic Achievement in Undergraduate College Students. Master's thesis, Bucknell University, Lewisburg, PA.

Therkelsen A (2010) Deciding on Family Holidays-Role Distribution and Strategies in Use. Journal of Travel \& Tourism Marketing 27(8), 765-779.

Tong S (2015) The Impact of Parental Behaviours on Children's Negative Emotions. Master's Thesis, University of Jyväskylä, Finland.

Touba JR (1979) Marriage and the family in Iran. In: Das MS and Bardis PD (eds) The Family in Asia. London: George Allen \& Unwin, pp. 208-244.

Veronneau MH, Koestner RF and Abela JRZ (2005) Intrinsic need satisfaction and well-being in children and adolescents: An application of the self-determination theory. Journal of Social and Clinical Psychology 24: 280-292.

Wang K-C, Hsieh A, Yeh Y, et al. (2004) Who is the decision-maker: The parents or the child in group packaged tours? Tourism Management 25(2): 183-194.

Weinstein SM and Mermelstein R (2007) Relations between daily activities and adolescent mood: The role of autonomy. Journal of Clinical Child and Adolescent Psychology 36(2): 182-194.

World Tourism Organization (2015) UNWTO: Tourism highlights 2015. Available at: http://www.eunwto.org/doi/pdf/10.18111/9789284416899 (accessed 1 March 2016).

Yeoman, I., McMahon-Beattie, U., Lord, D., and Parker-Hodds, L. (2012) Demography and Societal Change. In H. Schänzel, I. Yeoman, \& E. Backer (Eds.), Family Tourism: Multidisciplinary Perspectives (pp. 30-49). Bristol: Channel View Publications. 